2. The ionization constants of seven other mono-carboxy-naphthalene derivatives have been re-determined.

3. The place influence for a double union in the $\Delta^{2}$ position in respect to the carboxyl group has been shown to be a constant for the cyclic acids. The dangers of drawing conclusions from the ionization constants of unsaturated aliphatic acids where cis-trans isomerism due to the double union is possible, have been emphasized.

4. The place influence for a $\Delta^{1}$ double union has been shown to vary with the degree of conjugation and it is suggested that a quantitative interpretation of 'Thiele's Partial Valence Theory may be developed from this standpoint.

URBana, ILr.

[Contribution from the Laboratory of Physical, Chemistry, University of Wisconsin. ]

\title{
A CONTRIBUTION TO THE THERMAL CHEMISTRY OF PYRIDINE.
}

By J. Howard Mathews, Ellis L. Krauge and Van L. Bohnson.

Received January 11, 1917.

\section{Introduction.}

During the past few years considerable work has been done in this laboratory on the solubility of various inorganic salts in pyridine. A number of new compounds having pyridine of crystallization have been discovered, and the equilibria relations of these, together with those of many of the earlier known compounds, have been determined. ${ }^{1}$ It was frequently noted that the thermal effect accompanying the formation or the solution of these compounds was very appreciable.

The purpose of the work described in this paper was to measure the heat effects accompanying the act of taking on of pyridine of crystallization. Because of its analogy to the thermal effect accompanying the taking on of water of crystallization, which we call "heat of hydration," we shall, for lack of a better term, refer to the thermal effect under consideration as the "heat of pyridination."

This heat of pyridination was measured in the usual manner, i.e., by determining the heat of solution of the salt first without, and then with, its pyridine of crystallization, the difference between these values yielding the heat of pyridination.

${ }^{1}$ Kahlenberg and Brewer, J. Phys. Chem., I2, 282 (1908); Kahlenberg and Wittich, Ibid., I3, 427 (I909); McBride, Ibid., I4, I89 (I910); Walton and Judd, This Journal, 33, 1026 (1911); Cotton, M.S. Thesis, University of Wisconsin, 1911; Spero, B.S. Thesis, University of Wisconsin, I9I3; Deemer, M.S. Thesis, University of Wisconsin, I914; Mathews and Benger, J. Phys. Chem., 18, 264 (1914); Ritter, B.S. Thesis, University of Wisconsin, 1915 . 
Mathews and Germann, ${ }^{1}$ and others, have demonstrated the practicability of the Dewar cylinder as a protection against radiation in calorimetric measurements, and have shown that by its use a considerable degree of accuracy can be obtained. Although not capable of yielding the extreme accuracy attainable with the adiabatic calorimeter, this form of calorimeter mantle affords greater ease in the making of thermal measurements than does the adiabatic. It has been in use in this laboratory for a number of years, and has proven to be very efficient; others have also used it with gratifying results; a fact which has frequently been recorded in the literature. Because of the rapidity with which operations can be carried out, this device was especially suited to the measurement of the heats of solution of compounds having pyridine of crystallization. The time factor was important, as some of these compounds have a considerable vapor pressure at room temperatures and lose pyridine readily, although for the most part they are fairly stable.

\section{Apparatus.}

The apparatus used in the determination of the heats of solution of the mercury compounds described in this paper was a modification of that used by Krause, ${ }^{2}$ and was, with but few changes the one used by Rottman $^{3}$ to whom we are indebted for some preliminary work on the heats of solution of mercury compounds. The heats of solution and the specific heats of the resulting solutions were determined by means of the same apparatus, which is illustrated in Fig. I.

A large Dewar cylinder, A, was used as the outer jacket. Inside this cylinder, separated from it by an air space of about $\mathrm{I} \mathrm{cm}$. was the calorimeter proper B, which was insulated from the Dewar cylinder by cork points, $C$, at the bottom and near the top.

The calorimeter $\mathrm{B}$, of about $600 \mathrm{cc}$. capacity, $8 \mathrm{~cm}$. in diameter and $\mathrm{I} 2$ $\mathrm{cm}$. deep, was made of copper, nickel plated and highly polished on the outside, and heavily plated with silver on the inside surface, silver being used because it resists the action of the solutions worked with, while copper is readily attacked.

The apparatus was stoppered with a flat cork, $D$, which had been cut into two cylindrical halves, and then glued together again with a sheet of ebonite $2 \mathrm{~mm}$. thick between the halves. The ebonite served as an insulator

1 Mathews and Germann, J. Phys. Chem., I5, 73 (I9r r).

2 The heats of solution of the silver compounds were determined by means of another apparatus which differed from the one herein described in that a platinum calorimeter was used in place of the nickel-plated copper calorimeter. The specific heats of the solutions were measured in a separate, smaller Dewar cylinder which served as a calorimeter. The water equivalent of the heat of solution apparatus was calculated from the specific heats and weights of the parts; that of the specific heat apparatus was determined by the electrical method.

${ }^{3}$ Rottman, M. S. Thesis, University of Wisconsin, 1914. 
and prevented the warping generally experienced with large corks. A double layer of tinfoil to prevent loss of heat through the stopper, was glued to its lower and lateral surfaces, and the stopper was then cut into two semicircular halves. It was perforated as shown to accommodate the Beckmann thermometer $\vec{E}$ and the heating element $F$ in opposite halves of the stopper. Along the cut diameter two small holes were made, one for the stirrer $G$ and the other for the rod holding the platinum basket $\mathrm{H}$.

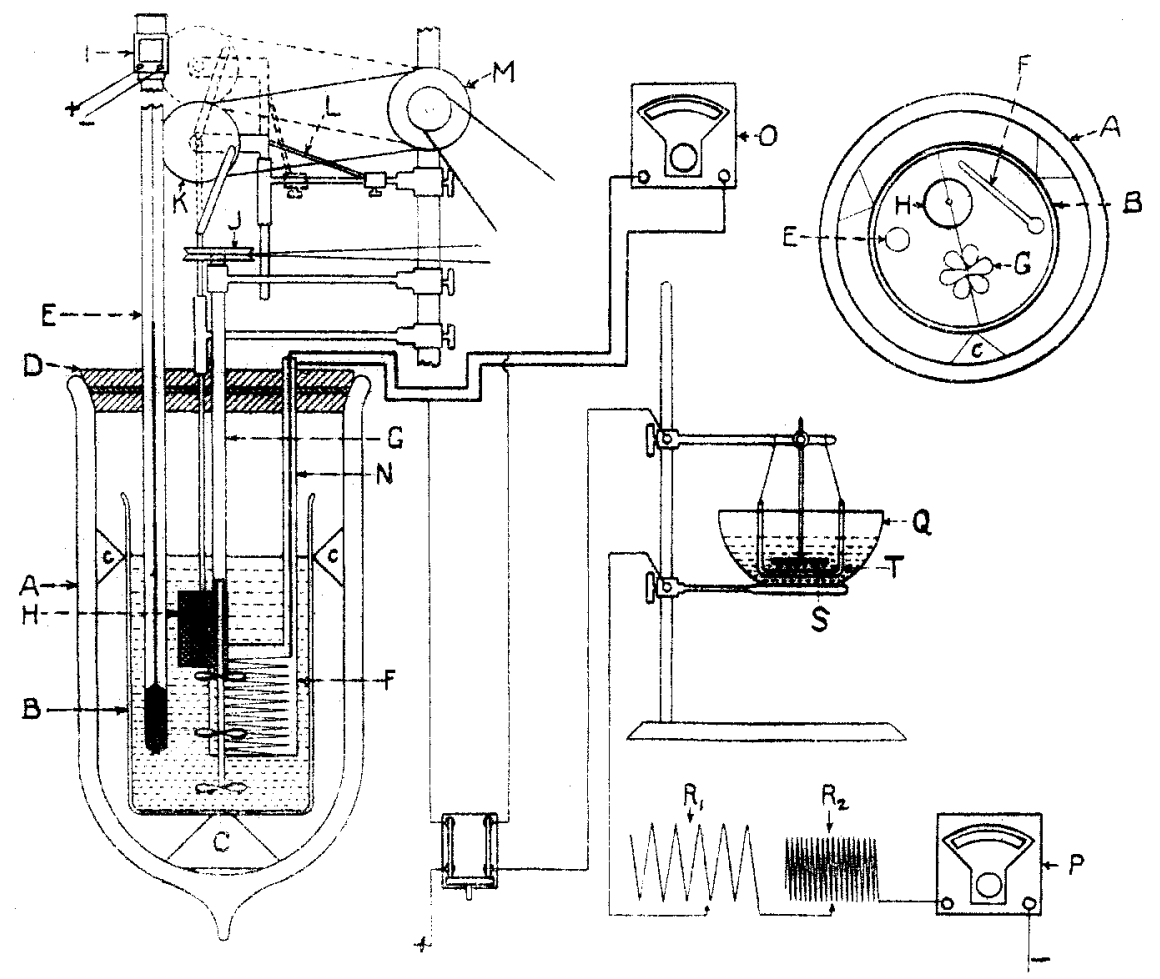

Fig. I.

The Beckmann thermometer $\mathrm{E}$ was held in position by means of a cork stopper (not shown in the diagram) fitting the hole, so that the thermometer bulb was always immersed in the liquid to the same depth. The heating element $F$ was suspended in like manner. The thermometer was carefully standardized before using, by comparison with a laboratory standard thermometer, corrections for which had been furnished by the United States Bureau of Standards. Both thermometers could be read to $0.001^{\circ}$. The comparison was made in an insulated calorimeter contained in a Dewar cylinder, the water being well stirred. The thermometers were tapped with a small buzzer I, for ten seconds before 
each temperature was read; a small reading telescope supported on the thermometer facilitated the reading. The probable error for the temperature readings being made in the course of this work was therefore not more than $\pm 0.001^{\circ}$.

The stirrer $G$ consisted of a silver rod mounted with three propellorlike blades of silver $2 \mathrm{~cm}$. long on either side of the rod. The end of the rod was cemented into a glass tube which led to a pulley, $J$. The speed of stirring was regulated by a resistance in the motor circuit. During the experiments described the rate was about 275 revolutions per minute. Neither the stirring nor the motion of the basket (to be described) had any appreciable thermal effect, the combined motions causing a rise in temperature of only about $0.001^{\circ}$ in ten minutes.

The cylindrical basket $\mathrm{H}, 2 \mathrm{~cm}$. in diameter and $6 \mathrm{~cm}$. long, made of fine platinum gauze, was fastened with platinum wire to a silver rod. This rod passed through an opening between the halves of the stopper, thence through a sleeve to a pitman leading to the eccentric $K$, which imparted an up and down thrust to the basket as the pulley revolved. The pulley $K$ could be raised or lowered at will by means of the arm $\mathrm{L}$ and clamped in any desired position by a set-screw. When raised, the basket was supported above the liquid in the calorimeter; when lowered, it would be entirely submerged and would be thrust up and down in the liquid. The double pulley $M$ allowed the basket to be plunged up and down, or to be held stationary, by merely shifting the belt with a touch of the finger from the fixed to the free pulley. During the process of solution the basket plunged up and down in the solvent at a rate of about I 25 times per minute.

The heating element $F$ was constructed as follows: a suitable length of No. 36 nichrome wire to give a resistance of about 40 ohms was wound at small intervals about a thin mica sheet, $3.5 \mathrm{~cm}$. by $4.5 \mathrm{~cm}$. in size. Two other sheets, a trifle larger, were placed on either side, and the resistance unit so prepared was slipped into a thin brass case made for the purpose by flattening a large brass tube. One end of the wire was soldered to the lower edge of the casing and the other to the end of a well-insulated heavy copper wire, which was contained in a small brass tube, N. The tube was firmly fastened to one of the upper corners of the case, and all joints were pressed together, soldered, and filed smooth. The heating element thus prepared was cleaned, plated with a thin coating of copper, and then with silver. The completed heating blade was $4 \mathrm{~cm}$. wide, $5 \mathrm{~cm}$. long, and about $2 \mathrm{~mm}$. thick. The brass tube $\mathrm{N}$ was $13 \mathrm{~cm}$. long, and $2.5 \mathrm{~cm}$. in diameter. Since the resistance of the heavy copper wire in the circuit was negligible in comparison with the resistance of the nichrome wire, the heating effect took place only in the blade of the heater. With a potential drop of about 30 volts across this resistance, the solu- 
tion could be heated sufficiently in two to three minutes (giving a rise in temperature of from $3^{\circ}$ to $4^{\circ}$ ) to determine its specific heat.

Across the terminals of this heating element were connected, by means of a very heavy insulated copper wire, the terminals of a Weston Direct Reading Laboratory Standard Voltmeter, $O$, having a $30 \mathrm{~cm}$. scale graduated to hundredths of a volt. A correction curve for the instrument was obtained by comparing it with a voltmeter of the same type which had been standardized by the United States Bureau of Standards. At the voltage used in these experiments, the correction to be applied to the scale reading was to. roo volt. Storage batteries were used as a source of current, and the voltage was kept at precisely the desired value by means of the sliding resistances $R_{1}$ and $R_{2}$ in the circuit.

An ammeter, $P$, was connected in series, and was used only to get an approximate value of the current.

The current passing through the heater was measured accurately by means of a Richards silver coulometer, $Q$. The anode $S$, consisting of a sheet of platinum foil heavily plated with electrolytic silver, fastened to a heavy platinum wire, was contained in a porous cup, $T, 6 \mathrm{~cm}$. in diameter and $7 \mathrm{~cm}$. high, suspended from the arm of the electrolyzing stand. The cathode was a platinum dish about $13 \mathrm{~cm}$. in diameter at the top and $4 \mathrm{~cm}$. deep. A neutral $15 \%$ solution of silver nitrate was used as electrolyte.

\section{Procedure.}

An exact amount of purified pyridine ( $400 \mathrm{~g}$, as this filled the calorimeter to the best working capacity) was weighed out in the calorimeter, and the vessel and its contents were allowed to come to a temperature slightly above or below room temperature, depending upon whether the thermal change would produce a rise or a fall in temperature, after which the calorimeter was placed in position in the Dewar cylinder. The salt to be used was weighed out in the platinum basket (in the ratio of I mol of salt to 200 mols of solvent). The stirrer was then adjusted, and the basket attached to the eccentric in such a manner that it was supported above the liquid. The two halves of the stopper, carrying the thermometer and the heating element, were pressed into place, and the motor started. Since the belt was on the free pulley, the basket remained stationary above the pyridine. The stirring was allowed to continue for ten minutes or more, until it was evident that the change in temperature had become regular. Temperature readings were taken every minute, and from the time-temperature curve thus obtained the radiation in the foreperiod was determined.

The belt was now shifted from the free to the fixed pulley and the arm $\mathrm{L}$ was adjusted so as to lower the basket into the solvent. At this instant the time and the temperature were noted. The basket plunged 
up and down, effecting complete solution in a short time, the maximum change in temperature taking place in all cases in about two minutes. The highest (or lowest) temperature was recorded, with the time, and readings were thereafter made each minute for about twenty minutes in order to obtain the radiation in the after-period.

The specific heats of the resulting solutions were sometimes obtained immediately after the above procedure, without removing the solution from the apparatus. This was especially easy when the heat of solution was negative. In most cases, however, the solution was removed, cooled to the desired temperature (about two degrees below room temperature), and a weighed amount of solution (400 g.) replaced in the calorimeter. The apparatus was then set up as before, and the stirring allowed to continue until the temperature change had become uniform. The coulometer having been made ready, the switch was closed, and the current was passed through the heater for a length of time necessary to produce a rise in temperature of about $4^{\circ}$. In all the results reported for mercury compounds $^{1}$ the voltage was kept at $30.1( \pm 0.01)$ by means of the sliding resistances. After cutting off the current, readings of temperature were taken each minute, as before, for about twenty minutes. Immediately after the current was cut off, the electrolyte was poured out of the coulometer. The silver deposit in the platinum dish was carefully washed with distilled water and with pure alcohol, and dried in an air bath at $115^{\circ}$ for two hours, allowed to cool in a desiccator, and weighed.

The water equivalent of the apparatus was obtained experimentally by passing a definite current through the heating element when the calorimeter contained a known weight of water.

\section{Materials Used.}

The pyridine used as a solvent and in the preparation of the various compounds was purified according to the method described by Wilcox. ${ }^{2}$ It was first allowed to stand over electrolytic stick potassium hydroxide for several months, was digested with potassium permanganate and barium oxide for about eight hours under a reflux condenser, and the fraction distilling over between I $14.6^{\circ}$ and I I $5.6^{\circ}$ at $737 \mathrm{~mm}$. was preserved for use. It was found that after the pyridine had been redistilled several times, the greater portion distilled over at $115.4^{\circ}$ at $737 \mathrm{~mm}$.

C. P. silver nitrate, mercuric chloride, and mercuric iodide were used. The silver nitrate was recrystallized from doubly distilled water. The mercury salts were found to be of a high degree of purity, and were not further purified.

The water used in the preparation of solutions and in washing the

1 The specific heats of solutions of the silver compounds were determined by means of another apparatus, the voltage used being smaller. (Note 2, p. 399.)

2 J. Phys. Chem., 13, 384 (1909). 
silver deposit in the coulometer was especially distilled for the purpose, as was also the alcohol used.

\section{Preparation and Analysis of Compounds.}

The two salts $\mathrm{AgNO}_{3} \cdot 3 \mathrm{C}_{5} \mathrm{H}_{5} \mathrm{~N}$ and $\mathrm{AgNO}_{3} .2 \mathrm{C}_{5} \mathrm{H}_{5} \mathrm{~N}$ were prepared according to the method described by Jörgensen, ${ }^{1}$ which in the case of the former consists essentially of simple crystallization from pyridine at room temperatures. In the case of the compound $\mathrm{AgNO}_{3} .2 \mathrm{C}_{5} \mathrm{H}_{5} \mathrm{~N}$ the silver nitrate was dissolved in as little water as possible, pyridine added in excess, and the salt caused to crystallize out by adding ether to the solution. The former salt, upon analysis by the Volhard method, gave $41.59 \% \mathrm{AgNO}_{3}$, whereas theory requires $41.60 \%$; the latter gave $51.40 \%$, whereas theory requires $51.80 \%$. That the pyridine does not interfere with this method of analysis was shown by Kahlenberg and Brewer. ${ }^{2}$ These investigators also showed that a compound $\mathrm{AgNO}_{3} .6 \mathrm{C}_{5} \mathrm{H}_{5} \mathrm{~N}$ exists, but it is stable at such low temperatures $\left(-25^{\circ}\right.$ to $\left.-50^{\circ}\right)$ that we did not attempt its preparation.

Cotton ${ }^{2}$ noted that there was considerable heat evolution when silver thiocyanate was dissolved in pyridine. This salt was prepared by treating pure silver nitrate solution with a solution of $C$. P. ammonium thiocyanate in the dark. 'The precipitate was washed by decantation eight times with distilled water, filtered off and heated in a drying oven at $65^{\circ} \mathrm{C}$. until nearly dry, after which it was dried several days under diminished pressure. When analyzed it contained $64.79 \%$ silver, whereas theory requires $65.04 \%$. The only crystalline compound of this salt with pyridine which was obtained corresponded with the formula $\mathrm{AgSCN}, \mathrm{C}_{5} \mathrm{H}_{5} \mathrm{~N}$. This was prepared by saturating about roo ec. of pyridine with silver thiocyanate at about $50^{\circ}$ and cooling overnight, whereupon the salt crystallized out. It was filtered quickly, using a filter pump, and the crystals rubbed until surface dry between sheets of filter paper. As it loses pyridine quite rapidly when exposed to the air, it was kept in tightly stoppered bottles. Upon analysis it gave $68.00 \% \mathrm{AgSCN}$, theory requiring $67.7 \mathrm{I} \%$. In making these analyses a weighed amount of the sample was heated carefully in a small porcelain crucible to drive off the pyridine and decompose the silver thiocyanate, after which the crucible and residue were heated with concentrated nitric acid in a covered beaker until all of the silver had gone into solution. 'The resulting solution was diluted with water and cooled, after which it was titrated as usual with freshly standardized ammonium thiocyanate solution.

It has been shown by $\mathrm{McBride}^{2}$ that the salts $3 \mathrm{HgCl}_{2} .2 \mathrm{C}_{5} \mathrm{H}_{5} \mathrm{~N}$, $\mathrm{HgCl}_{2} \cdot \mathrm{C}_{5} \mathrm{H}_{5} \mathrm{~N}$, and $\mathrm{HgCl}_{2} \cdot 2 \mathrm{C}_{5} \mathrm{H}_{5} \mathrm{~N}$ exist, and separate out in crystalline form within definite temperature ranges. These compounds have also been

I. prokt. Chem. 33, 501 (1886).

Loc. cit. 
previously described by Monari, ${ }^{1}$ by Lang, ${ }^{2}$ and by Pesci. ${ }^{3}$ The compound $\mathrm{HgI}_{2} .2 \mathrm{C}_{5} \mathrm{H}_{5} \mathrm{~N}$ was also first described by Monari, ${ }^{2}$ and later by other investigators. The solubility of mercuric iodide in pyridine has recently been determined by Ritter, ${ }^{4}$ who has shown that between the limits $-50^{\circ}$ and $+100^{\circ} \mathrm{C}$., $\mathrm{HgI}_{2},{ }_{2} \mathrm{C}_{5} \mathrm{H}_{5} \mathrm{~N}$ is the only compound of mercuric iodide and pyridine, although it occurs in two different crystalline forms.

The compound $\mathrm{HgCl}_{2}, 2 \mathrm{C}_{5} \mathrm{H}_{5} \mathrm{~N}$ separates from a pyridine solution of mercuric chloride below $76^{\circ}$. A solution saturated at $65^{\circ}$ was cooled and the salt allowed to crystallize. The crystals after being pressed were dried by placing them in a glass tube through which dry air was drawn at room temperature. Analyses yielded the following results:

$\begin{array}{cccc}\begin{array}{c}\text { Weight of } \\ \text { sample, g. }\end{array} & \begin{array}{c}\text { Weight of } \\ \text { HgS, g. }\end{array} & \begin{array}{c}\text { Percentage } \\ \text { of Hg. }\end{array} & \begin{array}{c}\text { Theoretical } \\ \% \mathbf{H g} .\end{array} \\ \text { I. I6I2 } & \text { I.6870 } & 46.69 & \\ 0.6289 & 0.9123 & 46.63 & 46.69\end{array}$

The compound separated in large needle-shaped crystals. It tends to lose pyridine in the air, and was therefore kept in tightly stoppered bottles.

An attempt was made to prepare the compounds $3 \mathrm{HgCl}_{2} .2 \mathrm{C}_{5} \mathrm{H}_{5} \mathrm{~N}$ and $\mathrm{HgCl}_{2} \cdot \mathrm{C}_{5} \mathrm{H}_{5} \mathrm{~N}$, which separate out at $\mathrm{II} 7^{\circ}$ and at $80^{\circ}$, respectively, by allowing them to crystallize from pyridine solution at these temperatures, using a method devised by Rottman, ${ }^{4}$ but the difficulty in freeing the crystals of all adhering pyridine at the temperatures of formation, and the fact that unless the pyridine is so removed the compounds will revert in whole or in part to $\mathrm{HgCl}_{2} .2 \mathrm{C}_{5} \mathrm{H}_{5} \mathrm{~N}$ caused the method to be abandoned. Recourse was then had to the methods described below.

The compound ${ }_{3} \mathrm{HgCl}_{2} .2 \mathrm{C}_{5} \mathrm{H}_{5} \mathrm{~N}$ was prepared as described by Pesci, ${ }_{4}$ by adding solid $\mathrm{HgCl}_{2} . \mathrm{C}_{5} \mathrm{H}_{5} \mathrm{~N}$ to a boiling $4 \%$ aqueous solution of mercuric chloride, until no more would dissolve, filtering, and allowing to cool. The product separated in white needle-shaped crystals, which were dried in the air overnight. Analyses of three separately prepared samples yielded the following results:

\begin{tabular}{|c|c|c|c|c|}
\hline 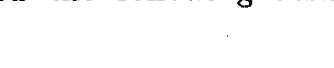 & $\begin{array}{l}\text { Weight of } \\
\text { sample, g. }\end{array}$ & $\begin{array}{c}\text { Weight of } \\
\mathrm{HgS}, \mathrm{g} .\end{array}$ & $\begin{array}{l}\text { Percentage } \\
\text { of } \mathrm{Hg} \text {. }\end{array}$ & $\begin{array}{c}\text { Theoretical } \\
\% \mathrm{Hg} .\end{array}$ \\
\hline (I) $\ldots$ & $0.744^{2}$ & 0.5336 & 61.82 & \\
\hline & 0.9477 & 0.6804 & 61.90 & \\
\hline (2). & 0.8426 & 0.6066 & 62.07 & \\
\hline & 0.8654 & 0.6234 & $62 . \mathrm{Ir}$ & 61.87 \\
\hline & 0.6944 & $0.499 \mathrm{I}$ & 61.97 & \\
\hline (3)... & $0.957^{\circ}$ & 0.6898 & 62.14 & \\
\hline
\end{tabular}

These three samples were kept separate in tightly stoppered bottles,

${ }^{1}$ Rev. di Chim. Med. Farm, 2, I90 (1884); Jahresber., I884, 629.

${ }^{2}$ Ber., 21, 1586 (I888).

${ }^{3}$ Gazz. chim. ital., [2] 25, 429 (1895).

4 Loc. cit. 
and the heat of solution was separately determined for each sample. The substance was stable in the air, but in the presence of pyridine vapor tended to form the compound $\mathrm{HgCl}_{2} .2 \mathrm{C}_{5} \mathrm{H}_{5} \mathrm{~N}$.

The compound $\mathrm{HgCl}_{2} . \mathrm{C}_{5} \mathrm{H}_{5} \mathrm{~N}$ was prepared as described by Lang. ${ }^{1}$ An aqueous solution of mercuric chloride was treated with an excess of pyridine. The voluminous white precipitate thus formed was boiled up with distilled alcohol, the solution filtered through a hot water funnel, and allowed to cool. The product separated in long, white, hair-like crystals, tending to form radiating aggregates. The crystals were filtered, pressed, and allowed to dry overnight in the air, as at ordinary temperatures the salt is quite stable. Analyses yielded the following results:

$\begin{array}{cccc}\begin{array}{c}\text { Weight of } \\ \text { sample, g. }\end{array} & \begin{array}{c}\text { Weight of } \\ \text { HgS, g. }\end{array} & \begin{array}{c}\text { Percentage } \\ \text { of } \mathrm{Hg} .\end{array} & \begin{array}{c}\text { Theoretical } \\ \% \mathrm{Hg} .\end{array} \\ 0.8130 & 0.5402 & 57.29 & \\ 0.7400 & 0.4920 & 57.32 & 57.23\end{array}$

The compound $\mathrm{HgI}_{2.2} \mathrm{C}_{5} \mathrm{H}_{5} \mathrm{~N}$ separates out from pyridine solution at ordinary temperatures, and was thus prepared. The white crystals were filtered, pressed, and dried in a long glass tube by passing over them a current of dry air. Analyses yielded the following:

$\begin{array}{cccc}\begin{array}{c}\text { Weight of } \\ \text { sample, g. }\end{array} & \begin{array}{c}\text { Weight of } \\ \text { HgS, g. }\end{array} & \begin{array}{c}\text { Percentage } \\ \text { of } \mathrm{Hg} .\end{array} & \begin{array}{c}\text { Theoretical } \\ \% \mathrm{Hg} .\end{array} \\ 0.9408 & 0.3540 & 32.45 & \\ \mathbf{1} .0332 & 0.3910 & 32.54 & 32.75 \\ 0.9502 & 0.3591 & 32.58 & \end{array}$

In weighing out the necessary amount of salt for use in determining its treat of solution, allowance was made for the fact shown in the analysis that all excess pyridine had not been removed. The salt is unstable in the air, decomposition making itself evident by a color change from white to red.

The method of analysis described by $\mathrm{McBride}^{1}$ was used for mercuric chloride and its compounds. The sample was dissolved in dilute hydrochloric acid and the solution diluted to about roo cc. Hydrogen sulfide was then passed through the solution in the cold until the mercuric sulfide was completely precipitated. The precipitate was collected upon a tared Gooch crucible, washed several times with hot distilled water, with alcohol, and with carbon disulfide, dried for two hours at $110^{\circ}$ in an oven, and weighed.

In the case of mercuric iodide and its compounds with pyridine, a method of analysis described by Ritter $^{1}$ was used. The sample was dissolved in an excess of potassium iodide solution, and diluted to about $250 \mathrm{cc}$. Hydrogen sulfide was passed through the solution in the cold until complete precipitation was effected. The precipitate was allowed to settle for an hour, and was then filtered, washed, dried, and weighed, as described above.

1 Loc. cit. 


\section{Calculations.}

$\mathrm{H}$, water equivalent of apparatus.

$Q$, quantity of heat (in calories) produced by current.

$\mathrm{W}$, weight of liquid (in grams).

$\mathrm{T}$, corrected rise (or lowering) of temperature.

C, current (amperes).

$t$, time of flow of current (minutes).

$\mathrm{R}$, resistance (ohms).

A, weight of silver (in grams).

E, volts.

$S$, specific heat.

$\mathrm{M}$, molecular weight of salt.

$x$, weight of salt used (grams).

$d \mathrm{~T}$, average rate of change of temperature in fore-period.

$d \mathrm{~T}^{\prime}$, average rate of change of temperature in after-period.

$n$, number of minutes in middle period.

(I) The water equivalent of the apparatus was calculated by means of the formula

$$
H=\frac{Q-W S T}{T} \text {. }
$$

Since $Q=C^{2} R t, \frac{E}{C}=R$, and $C=\frac{96500 A}{107.88 t}$, the following expression may be obtained:

$$
Q=\frac{96500 \mathrm{AE}}{107.88 \times 4.177}
$$

(The value for the Faraday is that recommended by Vinal and Bates, Bull. Bur. Stand., Io, 449; the Callendar-Barnes value for the electrical equivalent of the $21^{\circ}$ calorie is used)

$$
\text { or, } Q=\mathrm{KAE} \text {, where } \mathrm{K}=\frac{96500}{107.88 \times 4.177}=214.15 \text {. }
$$

Hence the first equation given above becomes

$$
\mathrm{H}=\frac{\mathrm{KAE}}{\mathrm{T}}-\mathrm{W}
$$

(the specific heat of water being taken as $\mathrm{I}$ ).

(2) The specific heats of the solutions used were obtained by substitution in the equation

which resolves into

$$
\mathrm{S}=\frac{\mathrm{Q} / \mathrm{T}-\mathrm{H}}{\mathrm{W}}
$$

$$
\mathrm{S}=\frac{\mathrm{KAE} / \mathrm{T}-\mathrm{H}}{\mathrm{W}} .
$$

(3) The heats of solution were obtained by means of substitution in Heat of solution $=\mathrm{TM} / x(\mathrm{WS}+\mathrm{H})$. 
(4) The corrected rise in temperature $T$ was obtained by adding to the observed rise the correction for the thermometer $\mathrm{C}_{1}$ obtained from the standardization curve, and the radiation correction $\mathrm{C}_{2}$ which was calculated by means of the expression

$$
C_{2}=n / 2\left(d \mathrm{~T}^{\top}+d \mathrm{~T}^{\prime}\right) \text {. }
$$

All experimental work was conducted with an endeavor to make the radiation of heat to the calorimeter in the fore-period as nearly equal as possible to the radiation from the calorimeter in the after-period, thus minimizing this correction. The values for $d \mathrm{~T}$ and $d^{\prime} \mathrm{T}^{\prime}$ were taken to be - when the temperature was rising, and + when it was falling, and the correction $\mathrm{C}_{2}$ was added to the observed change in temperature.

(5) The necessary correction for the part of the current passing through the voltmeter (and hence not converted into heat in the heating element) was determined by passing the same strength current used in the specific heat determinations through the voltmeter and coulometer in series with each other, for a measured length of time (several hours). It was found that this current would deposit in one minute $0.0000633 \mathrm{~g}$. of silver.

\section{Results.}

The heats of solution of silver nitrate, silver thiocyanate, mercuric chloride, mercuric iodide, and their various "pyridinates," with the specific heats of pure pyridine and of the resulting solutions, are given in Tables I to XII. In each case $400 \mathrm{~g}$. of pyridine were used, with such amounts of salt as would make the ratio of salt to pyridine I mol of the former to 200 mols of the latter.

It should be noted that the mean value of the specific heat obtained in the various determinations was used in the calculation of the heats of solution. It will also be noted that the specific heats of the various solutions are approximately the same, or that the difference in their values does not exceed the possible experimental error. This of course should be the case since these solutions vary from one another in composition only by very small amounts of pyridine.

DETERMINATION OF WATER Equivalent.

1.-Combined Heat of Solution and Specific Heat Apparatus.

$\begin{array}{ll}\begin{array}{l}\text { Weight of } \\ \text { silver, } \mathrm{g} .\end{array} & \text { Volts. } \\ 0.2 \mathrm{I} 55 & 30 . \mathrm{I} \\ 0.2643 & 30 . \mathrm{I} \\ 0.2837 & 30.1 \\ 0.2248 & 28.25 \\ 0.2359 & 30.1 \\ 0.2323 & 30.1\end{array}$

400 g. water used.

$\begin{array}{cc}\begin{array}{c}\text { Temperature } \\ \text { change. }\end{array} & \begin{array}{c}\text { Water equiva- } \\ \text { lent, 8. }\end{array} \\ 3.194^{\circ} & 34.91 \\ 3.917^{\circ} & 34.83 \\ 4.210^{\circ} & 34.38 \\ 3.123^{\circ} & 35.48 \\ 3.498^{\circ} & 34.71 \\ 3.441^{\circ} & 35.16\end{array}$

Mean, 34.9r

Correction: 5.10 g. of silver plate were later added to the calorimeter. When corrected for this addition, the value of the water equivalent becomes 35.20 . 
II.-Specific Heat Apparatus (mentioned in note 2, page 399).

Weight of

silver, $\mathrm{g}$.

0.3950

0.3825

0.3482

0.3074

0.3150

0.3388

0.2510
Voits.

7.17

7.04

$5 \cdot 46$

$5.6 \mathrm{I}$

$5 \cdot 77$

6.20

6.84
Temperature

change.

$2.784^{\circ}$

2. $642^{\circ}$

I. $866^{\circ}$

I. $698^{\circ}$

I . $78 \mathrm{I}^{\circ}$

$2.066^{\circ}$

I. $683^{\circ}$
Water equiva-

lent, 8

I $8.6 \mathrm{I}$

19.07

I8. 98

I8. 30

I9. 35

I8. 54

I 9.26

I99. 2 g. water used.

Mean, I 8.87

III.-Heat of Solution Apparatus, 5.88 (see note 2, page 399).

TABLE I.-SPecific Heat OF Pyridine (AT $21^{\circ}$ ).

$\begin{array}{lcccc}\begin{array}{l}\text { Weight of } \\ \text { silver, g. }\end{array} & \text { Volts. } & \begin{array}{c}\text { Temperature } \\ \text { change. }\end{array} & \begin{array}{c}\text { Weight of } \\ \text { pyridine, g. }\end{array} & \begin{array}{c}\text { Specific } \\ \text { heat. }\end{array} \\ 0.0991 & 30 . \mathrm{I} & 3.344^{\circ} & 400 & 0.3903 \\ 0.0900 & 30 . \mathrm{I} & 3.027^{\circ} & 400 & 0.3919 \\ 0.1171 & 30 . \mathrm{I} & 3.950^{\circ} & 400 & 0.3904 \\ 0.1143 & 30 . \mathrm{I} & 3.853^{\circ} & 400 & 0.3908 \\ 0.1244 & 30 . \mathrm{I} & 4.190^{\circ} & 400 & 0.3912 \\ \text { H } & & & & \\ \end{array}$

$\begin{array}{cccc}\text { TABLE II.-AgNO } & \text { AN PXRIDINE. } & \\ \begin{array}{c}\text { Weight of } \\ \text { salt, g. }\end{array} & \begin{array}{c}\text { Weight of } \\ \text { pyridine, g. }\end{array} & \begin{array}{c}\text { Temperature } \\ \text { change. }\end{array} & \begin{array}{c}\text { Heat of } \\ \text { solution. }\end{array} \\ 4.2983 & 400 & +2.680^{\circ} & +16,995 \mathrm{cal} . \\ 4.2983 & 400 & 2.693^{\circ} & 17,077\end{array}$

$\mathrm{H}=5.88$

Mean, $+17,036 \mathrm{cal}$.

Weight of silver, $g$.

Volts.

Temperature

Weight of

$0.1500 \quad 6.60$

change. solution, $g$.

Specific

o. 1660

5.20

I $.950^{\circ}$

I97. 3

o. 3801

$0.184 \mathrm{I}$

5.06

$2.108^{\circ}$

$197 \cdot 4$

0.3847

$0.175^{\circ}$

$4.8 \mathrm{I}$

I. $916^{\circ}$

I97. 6

0.3834

$197 \cdot 5$

0.3809

$\mathrm{H}=\mathrm{I} 8.87$

Mean, 0.3823

TABLE III.- $\mathrm{AgNO}_{3} \cdot \mathrm{C}_{6} \mathrm{H}_{5} \mathrm{~N}$ IN Pyridine.

\section{Weight of \\ salt, $\mathrm{g}$.}

$$
\text { I0. } 2983
$$

IO. 2983

Io. 2983

$$
\mathrm{H}=5.88
$$

\section{Weight of}

silver, 8 .

o. 1492

o. 1872
Weight of

pyridine, $\mathbf{g}$.

$$
400
$$

400

400

$\mathrm{H}=\mathrm{I} 8.87$
- Temperature

change.

$-0.404^{\circ}$

$0.402^{\circ}$

$0.394^{\circ}$

Weight of solution, $g$.

I97. 3

197.4
Heat of solution.

$-2,632 \mathrm{cal}$.

2,620

2,567

Mean, -2,606 cal.

Temperatu
change.

I. $372^{\circ}$

2. $16 \mathrm{I}^{\circ}$
Specific

○. 3876

0.3874

Mean, 0.3875 


$$
\begin{aligned}
& \text { Weight of } \\
& \text { salt, g. } \\
& 8.2959 \\
& 8.2959 \\
& 8.2959
\end{aligned}
$$

\section{TABLE IV.-AgNO $\mathrm{NO}_{3} \mathrm{C}_{6} \mathrm{H}_{5} \mathrm{~N}$ IN Pyridine.}

$$
H=5.88
$$

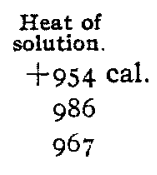

Mean, +969 cal.

(Note: In the above calculations the specific heat is taken as 0.3875 , which is the specific heat of the solution of $\mathrm{AgNO}_{3}{ }_{3} \mathrm{C}_{5} \mathrm{H}_{5} \mathrm{~N}$ in pyridine. These two solutions differ only by about 2 grams of pyridine in a total weight of over $400 \mathrm{~g}$. This slight difference in concentration has no measurable effect on the specific heat of the solution.)

$$
\begin{aligned}
& \text { Weight of } \\
& \text { salt, g. } \\
& 4.1989 \\
& 4.1989 \\
& H=5.88
\end{aligned}
$$

\section{TABLE V.-AgSCN IN PYRIDINE.}

$\begin{array}{ccc}\begin{array}{c}\text { Weight of } \\ \text { pyridine, } \mathrm{g} .\end{array} & \begin{array}{c}\text { Temperature } \\ \text { change. }\end{array} & \begin{array}{c}\text { Heat of } \\ \text { solution. }\end{array} \\ 400 & +0.691^{\circ} & +4,361 \mathrm{cal} . \\ 400 & 0.692^{\circ} & 4.367\end{array}$

$\begin{array}{lr}\qquad H=5.88 \\ \begin{array}{ll}\text { Weight of } \\ \text { silver, } 8 .\end{array} \\ 0.1739 & \text { Volts. } \\ 0.1831 & 4.79 \\ 0.1641 & 5.03 \\ & 5.15\end{array}$

$$
H=18.87
$$

Temperature
change.
$1.901^{\circ}$
$2.108^{\circ}$
$1.924^{\circ}$

emperature

I. $901^{\circ}$

I. $924^{\circ}$
Mean, $+4,364$ cal.

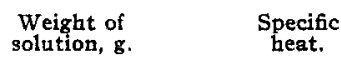

0.3792

I97.0
Mean, 0.3805

TABLE VI.-AgSCN. $\mathrm{C}_{6} \mathrm{H}_{5} \mathrm{~N}$ IN PyRIDINE.

$\begin{array}{rccc}\begin{array}{c}\text { Weight of } \\ \text { salt, g. }\end{array} & \begin{array}{c}\text { Weight of } \\ \text { pyridine, }\end{array} & \begin{array}{c}\text { Temperature } \\ \text { change. }\end{array} & \begin{array}{c}\text { Heat of } \\ \text { solution. }\end{array} \\ 6.1989 & 400 & +0.08^{\circ} & +24 \mathrm{cal} . \\ 6.1989 & 400 & 0.04 \mathrm{I}^{\circ} & 260 \\ & & & \text { Mean, +25o cal. }\end{array}$

(The specific heat of the solution is assumed to be the same as that of the solution in Table V.)

$\begin{gathered}\text { Weight of } \\ \text { salt, } \mathbf{g}\end{gathered}$
6.8696
6.8696
6.8696
6.8696
6.8696

\section{Weight of} silver, $\mathrm{g}$.

0.0889

0.1363

0.9770

0.0983

TABLE
Weight of
pyridine, $g$.
400
400
400
400
400

VII.- $\mathrm{HgCl}_{2}$ IN PYRIDINE.

Volts.
30.1
30.1
30.1
30.1

$\begin{gathered}\text { Temperature } \\ \text { change. }\end{gathered}$
$2.950^{\circ}$
$4.584^{\circ}$
$3.240^{\circ}$
$3.259^{\circ}$

Temperature

$2.950^{\circ}$

$4.584^{\circ}$

$3.259^{\circ}$

Temperature
change.
$+1.743^{\circ}$
$1.743^{\circ}$
$1.740^{\circ}$
$1.745^{\circ}$
$1.744^{\circ}$

Heat of solution. I 3,387

I 3,364

13,403

I 3,395
$+13,387$ cal.

\begin{tabular}{cc} 
Mean, & $+13.387 \mathrm{cal}$. \\
$\begin{array}{c}\text { Weight of } \\
\text { solution, } \mathrm{g} .\end{array}$ & $\begin{array}{c}\text { Specific } \\
\text { heat. }\end{array}$ \\
406.87 & 0.3909 \\
400.00 & 0.3912 \\
406.87 & 0.3912 \\
406.87 & 0.3913 \\
\hline
\end{tabular}

Mean, 0.39 I 
TABLE VIII.- ${ }_{3} \mathrm{HgCl}_{2}, 2 \mathrm{C}_{6} \mathrm{H}_{5} \mathrm{~N}$ in PyRIDINE.

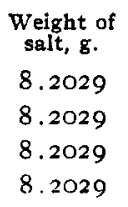

Weight of silver, $\mathrm{g}$.

o. 1187

o. I I 76

o. 1293

0.1264

Weight of salt, $\mathrm{g}$.

8.8695

8.8695

8.8695 Weight of
silver, $g$.

0.1207

0.0903

o. II6I

0.1087

Weight of
pyridine, $g$
400
400
400
400

400

400

400
Heat of solution.

$+4,974$ cal.

4,967

4,990

4,967

Mean, $+4,974 \mathrm{cal}$.

$\begin{array}{rccc}\text { Volts. } & \begin{array}{c}\text { Temperature } \\ \text { change. }\end{array} & \begin{array}{c}\text { Weight of } \\ \text { solution, } 8 .\end{array} & \begin{array}{c}\text { Specific } \\ \text { heat. }\end{array} \\ 30 . I & 3.994^{\circ} & 400 & 0.3909 \\ 30 . I & 3.991^{\circ} & 400 & 0.3869 \\ 30 . I & 4.362^{\circ} & 400 & 0.3896 \\ 30 . I & 4.251^{\circ} & 400 & 0.3911 \\ H=35.20 & & & \text { Mean, } 0.3896\end{array}$

TABLE IX.- $\mathrm{HgCl}_{2} \cdot \mathrm{C}_{5} \mathrm{H}_{5} \mathrm{~N}$ IN PyRIDINE.

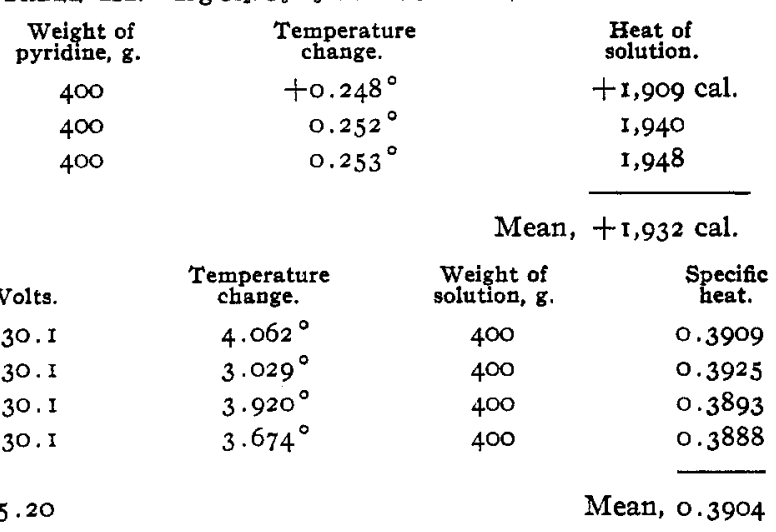

TABLE X.- $\mathrm{HgCl}_{2} .2 \mathrm{C}_{5} \mathrm{H}_{5} \mathrm{~N}$ IN PyRIDINE.

Weight of
salt, g.
I0 .8695
I0 .8695
10. 8695

Weight of silver, $g$.

0.0726

o. 1267

0.1003

o. 1340

\begin{tabular}{|c|}
\hline $\begin{array}{l}\text { Weight of } \\
\text { pyridine, } g\end{array}$ \\
\hline 400 \\
\hline 400 \\
\hline 400 \\
\hline
\end{tabular}

Volts.

30.1

30.1

30.1

30.1
Temperature
change.
$-0.694^{\circ}$
$0.693^{\circ}$
$0.691^{\circ}$

Mean, 0.3896 
TABIE XI.-HgIn IN Pyridine.

Weight of
salt, $g$.
I I . 4973
II . 4973
II. 4973

Weight of
silver, g.
O. 1275
O. 1295
O. I22I

Weight of salt, $\mathrm{g}$.

I 3.4973

r 3.4973

I 3.4973

Weight of
silver, g.

O. I 285

0.1215

O. IO4I

0.1235

Weight of
pyridine, $g$
400
400
400

Temperature

change.

$+1.317^{\circ}$

I. $323^{\circ}$
I. $322^{\circ}$

$$
\begin{gathered}
\begin{array}{c}
\text { Heat of } \\
\text { solution. }
\end{array} \\
+9,946 \text { cal. } \\
9,984 \\
9,992
\end{gathered}
$$

\begin{tabular}{|c|c|c|c|}
\hline $\begin{array}{l}\text { Weight of } \\
\text { pyridine, } 8\end{array}$ & $\begin{array}{c}\text { Temperature } \\
\text { change. }\end{array}$ & & $\begin{array}{l}\text { Heat of } \\
\text { solution. }\end{array}$ \\
\hline 400 & $-0.647^{\circ}$ & & $-4,9$ I 3 cal. \\
\hline 400 & $0.647^{\circ}$ & & 4,913 \\
\hline 400 & $0.650^{\circ}$ & & 4,936 \\
\hline & & Mean, & $-4,92$ I cal. \\
\hline Volts. & $\begin{array}{c}\text { Temperature } \\
\text { change. }\end{array}$ & $\begin{array}{l}\text { Weight of } \\
\text { solution, } g \text {. }\end{array}$ & $\begin{array}{l}\text { Specific } \\
\text { heat. }\end{array}$ \\
\hline 30.1 & $4.413^{\circ}$ & 400 & 0.3812 \\
\hline 30.1 & $4.201^{\circ}$ & 400 & $0.378 \mathrm{I}$ \\
\hline 30.1 & $3.592^{\circ}$ & 400 & 0.3791 \\
\hline 30.1 & $4.256^{\circ}$ & 400 & 0.3796 \\
\hline
\end{tabular}

Mean, $+9,974$ cal.

$\begin{array}{rccc}\text { Volts. } & \begin{array}{c}\text { Temperature } \\ \text { change. }\end{array} & \begin{array}{c}\text { Weight of } \\ \text { solution, }\end{array} & \begin{array}{c}\text { Specific } \\ \text { heat. }\end{array} \\ 30 . \mathrm{I} & 4.402^{\circ} & 400 & 0.3787 \\ 30 . \mathrm{I} & 4.466^{\circ} & 400 & 0.3792 \\ 30.1 & 4.217^{\circ} & 400 & 0.3786 \\ \mathrm{H}=35.20 & & & \text { Mean, } 0.3788\end{array}$

TABLE XII.- $\mathrm{HgI}_{2.2} \mathrm{C}_{5} \mathrm{H}_{5} \mathrm{~N}$ IN PyRIDINE.

From the above values for the heats of solution, the thermal changes taking place in the formation of the various pyridinates may be calculated, by means of the following equations:

(The symbol " $p y$ " indicates 200 mols of pyridine for one mol of salt.)

(1) $\quad \mathrm{AgNO}_{3}+p y=\mathrm{AgNO} \cdot p y+17,036 \mathrm{cal}$.

(2) $\mathrm{AgNO}_{3} \cdot 3 \mathrm{C}_{5} \mathrm{H}_{6} \mathrm{~N}+p y=\mathrm{AgNO}_{3} \cdot p y-2,606 \mathrm{cal}$.

(3) $\mathrm{AgNO}_{3}+{ }_{3} \mathrm{C}_{6} \mathrm{H}_{6} \mathrm{~N}=\mathrm{AgNO}_{3} \cdot \mathrm{C}_{5} \mathrm{H}_{5} \mathrm{~N}+19,636 \mathrm{cal}$.

(1) $\mathrm{AgNO}_{3}+p y=\mathrm{AgNO}_{3} \cdot p y+17,036 \mathrm{cal}$.

(4) $\mathrm{AgNO}_{3} \cdot 2 \mathrm{C}_{5} \mathrm{H}_{5} \mathrm{~N}+p y=\mathrm{AgNO}_{3} \cdot p y+969 \mathrm{cal}$.

(5) $\mathrm{AgNO}_{3}+{ }_{2} \mathrm{C}_{5} \mathrm{H}_{6} \mathrm{~N}=\mathrm{AgNO}_{3} .2 \mathrm{C}_{5} \mathrm{H}_{5} \mathrm{~N}+16,067 \mathrm{cal}$.

(3) $\mathrm{AgNO}_{3}+{ }_{3} \mathrm{C}_{5} \mathrm{H}_{5} \mathrm{~N}=\mathrm{AgNO}_{3} \cdot \mathrm{C}_{5} \mathrm{H}_{5} \mathrm{~N}+19,636 \mathrm{cal}$.

(5) $\mathrm{AgNO}_{3}+{ }_{2} \mathrm{C}_{5} \mathrm{H}_{6} \mathrm{~N}=\mathrm{AgNO}_{3} .2 \mathrm{C}_{5} \mathrm{H}_{5} \mathrm{~N}+16,067 \mathrm{cal}$.

(6) $\mathrm{AgNO}_{5.2} \mathrm{C}_{5} \mathrm{H}_{5} \mathrm{~N}+\mathrm{C}_{6} \mathrm{H}_{5} \mathrm{~N}=\mathrm{AgNO}_{3.3} \mathrm{C}_{5} \mathrm{H}_{5} \mathrm{~N}+3.569 \mathrm{cal}$.

(7) AgSCN + py = AgSCN.py $+4,364 \mathrm{cal}$.

(8) AgSCN.C. $\mathrm{H}_{5} \mathrm{~N}+p y=$ AgSCN.py $+250 \mathrm{cal}$.

(9) $\mathrm{AgSCN}+\mathrm{C}_{5} \mathrm{H}_{5} \mathrm{~N}=\mathrm{AgSCN} \cdot \mathrm{C}_{5} \mathrm{H}_{5} \mathrm{~N}+{ }_{4}$, I I 4 cal. 
(Io) $\mathrm{HgCl}_{2}+p y=\mathrm{HgCl}_{2} \cdot p y+\mathrm{I} 3,387$ cal.

(II) ${ }_{3} \mathrm{HgCl}_{2} .2 \mathrm{C}_{5} \mathrm{H}_{5} \mathrm{~N}+p y={ }_{3} \mathrm{HgCl}_{2} . p y+14,922$ cal.

(I $a$ ) or $\mathrm{HgCl}_{2} \cdot{ }^{2} / \mathrm{C}_{6} \mathrm{H}_{5} \mathrm{~N}+p y=\mathrm{HgCl}_{2} \cdot p y+4,974$ cal.

(I2) $3 \mathrm{HgCl}_{2}+{ }_{2} \mathrm{C}_{6} \mathrm{H}_{6} \mathrm{~N}={ }_{3} \mathrm{HgCl}_{2} .2 \mathrm{C}_{5} \mathrm{H}_{5} \mathrm{~N}+25,239$ cal.

(12a) or $\mathrm{HgCl}_{2}+{ }^{2} /{ }_{3} \mathrm{C}_{5} \mathrm{H}_{6} \mathrm{~N}=\mathrm{HgCl}_{2} \cdot{ }_{2} /{ }_{3} \mathrm{C}_{5} \mathrm{H}_{5} \mathrm{~N}+8,4 \mathrm{I} 3 \mathrm{cal}$.

(Io) $\mathrm{HgCl}_{2}+p y=\mathrm{HgCl}_{2} \cdot p y+\mathrm{I} 3,387 \mathrm{cal}$.

(I3) $\mathrm{HgCl}_{2} \cdot \mathrm{C}_{5} \mathrm{H}_{5} \mathrm{~N}+p y=\mathrm{HgCl}_{2} . p y+1,932$ cal.

(14) $\mathrm{HgCl}_{2}+\mathrm{C}_{5} \mathrm{H}_{5} \mathrm{~N}=\mathrm{HgCl}_{2} \cdot \mathrm{C}_{6} \mathrm{H}_{5} \mathrm{~N}+\mathrm{II}, 455$ cal.

(10) $\mathrm{HgCl}_{2}+p y=\mathrm{HgCl}_{2} . p y+\mathrm{I}_{3,387} \mathrm{cal}$.

(15) $\mathrm{HgCl}_{2.2} \mathrm{C}_{5} \mathrm{H}_{5} \mathrm{~N}+p y=\mathrm{HgCl}_{2} . p y-5,359 \mathrm{cal}$.

(16) $\mathrm{HgCl}_{2}+{ }_{2} \mathrm{C}_{5} \mathrm{H}_{6} \mathrm{~N}=\mathrm{HgCl}_{2.2} \mathrm{C}_{6} \mathrm{H}_{5} \mathrm{~N}+18,746$ cal.

(I6) $\mathrm{HgCl}_{2}+{ }_{2} \mathrm{C}_{5} \mathrm{H}_{5} \mathrm{~N}=\mathrm{HgCl}_{2} .2 \mathrm{C}_{5} \mathrm{H}_{5} \mathrm{~N}+\mathrm{I} 8,746$ cal.

(I4) $\mathrm{HgCl}_{2}+\mathrm{C}_{5} \mathrm{H}_{5} \mathrm{~N}=\mathrm{HgCl}_{2} \cdot \mathrm{C}_{5} \mathrm{H}_{5} \mathrm{~N}+\mathrm{II}, 455$ cal.

(I7) $\mathrm{HgCl}_{2} \cdot \mathrm{C}_{5} \mathrm{H}_{5} \mathrm{~N}+\mathrm{C}_{6} \mathrm{H}_{5} \mathrm{~N}=\mathrm{HgCl}_{2} \cdot 2 \mathrm{C}_{5} \mathrm{H}_{5} \mathrm{~N}+7,29$ I cal.

(18) $\mathrm{HgI}_{2}+p y=\mathrm{HgI}_{2} \cdot p y+9,974$ cal.

(19) $\mathrm{HgI}_{2.2} \mathrm{C}_{5} \mathrm{H}_{5} \mathrm{~N}+p y=\mathrm{HgI}_{2} \cdot p y-4,92 \mathrm{I}$ cal.

(2o) $\mathrm{HgI}_{2}+{ }_{2} \mathrm{C}_{8} \mathrm{H}_{5} \mathrm{~N}=\mathrm{HgI}_{2.2} \mathrm{C}_{5} \mathrm{H}_{5} \mathrm{~N}+\mathrm{r}_{4}, 895 \mathrm{cal}$.

\section{Summary.}

(I) It is evident that the thermal effect accompanying the combination of metallic salts with organic compounds of crystallization may in many cases be of considerable magnitude; in fact, the values are comparable with the analogous heats of hydration of such substances as sodium sulphate.

(2) A satisfactory apparatus for the measurement of heats of solution and specific heats of solutions has been devised and described. It has been applied to the measurement of the heats of solution in pyridine of silver nitrate, silver thiocyanate, mercuric chloride, and mercuric iodide and their compounds with pyridine. The values thus obtained have been used in calculating the "heats of pyridination" of these latter compounds.

Madison, Wis.

[CONTRIBUTION FROM THE DEPARTMENT OF ChEMISTRY OF THE UNIVERSITY OF Cincinnati.]

\section{ALIPHATIC HYDROXYLAMMONIUM SALTS AND HYDROXAMIC ACIDS WITH HALOGEN SUBSTITUENTS.}

By I,AUDER WiLliam JoNes and LouIs F. Werner.

Received December 7, 1916.

A few experiments described in scattered articles indicate that aliphatic hydroxamic acids and their derivatives will be found to show a pronounced tendency to undergo the Beckmann rearrangement in a manner quite similar to that so frequently observed in the study of aromatic hydroxamic acids. Many interesting reactions of this type suggest themselves when the possible rearrangements of simple aliphatic hydroxamic acids with halogen substituents are considered. It is our intention to make a study of the hydroxamic acids described in this article from this point of view. 